\title{
Structural and Surface Compatibility Study of Modified Electrospun Poly $(\varepsilon$-caprolactone) (PCL) Composites for Skin Tissue Engineering
}

\author{
Kajal Ghosal, ${ }^{1,2,4}$ Anton Manakhov, ${ }^{3}$ Lenka Zajíčková, ${ }^{3}$ and Sabu Thomas ${ }^{1}$
}

Received 28 October 2015; accepted 4 February 2016; published online 16 February 2016

\begin{abstract}
In this study, biodegradable poly( $\varepsilon$-caprolactone) (PCL) nanofibers (PCL-NF), collagen-coated PCL nanofibers (Col-c-PCL), and titanium dioxide-incorporated PCL $\left(\mathrm{TiO}_{2}\right.$-i-PCL) nanofibers were prepared by electrospinning technique to study the surface and structural compatibility of these scaffolds for skin tisuue engineering. Collagen coating over the PCL nanofibers was done by electrospinning process. Morphology of PCL nanofibers in electrospinning was investigated at different voltages and at different concentrations of PCL. The morphology, interaction between different materials, surface property, and presence of $\mathrm{TiO}_{2}$ were studied by scanning electron microscopy (SEM), Fourier transform IR spectroscopy (FTIR), contact angle measurement, energy dispersion X-ray spectroscopy (EDX), and Xray photoelectron spectroscopy (XPS). MTT assay and cell adhesion study were done to check biocompatibilty of these scaffolds. SEM study confirmed the formation of nanofibers without beads. FTIR proved presence of collagen on PCL scaffold, and contact angle study showed increment of hydrophilicity of Col-c-PCL and $\mathrm{TiO}_{2}$-i-PCL due to collagen coating and incorporation of $\mathrm{TiO}_{2}$, respectively. EDX and XPS studies revealed distribution of entrapped $\mathrm{TiO}_{2}$ at molecular level. MTT assay and cell adhesion study using L929 fibroblast cell line proved viability of cells with attachment of fibroblasts over the scaffold. Thus, in a nutshell, we can conclude from the outcomes of our investigational works that such composite can be considered as a tissue engineered construct for skin wound healing.
\end{abstract}

KEY WORDS: compatibility study; composites; electrospinning; PCL; skin tissue engineering.

\section{INTRODUCTION}

Tissue engineered cell transplantations $(1,2)$ are gaining importance for the patients suffering from tissue malfunctioning or loss due to some injuries, accidents, or other damages. Though tissue engineering emerged in early 1990s, still more researches are being continued to improve their functionality towards the cell transplantation (3). In tissue engineering, cells are initially seeded on a porous, degradable, mechanically strong, stable threedimensional passive structure with biocompatible surface, known as scaffold (4-6). There are different methods for scaffold fabrication and electrospinning is one of the most easiest and economical process $(7,8)$. Since 1930s (6), the electrospinning process is being widely used for scaffold preparation from different polymers. It produces micro- to nanofibrous-based scaffolds with desired porosity, biocompatibility, and enhanced specific surface area and also with proper mechanical stability (9). So structurally,

\footnotetext{
${ }^{1}$ Centre for Nanoscience and Nanotechnology, Mahatma Gandhi University, Priyadarshini Hills, Kottayam, Kerala 686560, India.

${ }^{2}$ Dr. B. C. Roy College of Pharmacy and Allied Health Sciences, Durgapur, 713206, India.

${ }^{3}$ Plasma Technologies, Central European Institute of Technology, Masaryk University, Brno, 61137, Czech Republic.

${ }^{4}$ To whom correspondence should be addressed. (e-mail: kajal.ghosal@gmail.com)
}

chemically, and mechanically, these electrospun scaffolds bear a resemblance-like extracellular matrix (ECM) of tissues $(10)$. The different synthetic polymers $(11,12)$ such as polyglycolide (PGA) (13), polyvinyl pyrrolidone (PVP) (14), and their copolymers poly(lactide-co-glycolide) (PLGA) (15), poly( $\varepsilon$-caprolactone) (PCL) (16), and polyurethane (PU) (17) have been widely used in electrospinning process. Other natural polymers such as collagen, fibronectin, laminin, alginic acid, and chitosan can be also electrospun for producing nanofibrous scaffolds $(18,19)$.

PCL, a semi-crystalline aliphatic polyester, belongs to the group of degradable polymers due to the susceptibility to hydrolytic cleavage of the ester bond. This property, along with good compatibility and easy processing (melting point at $60^{\circ} \mathrm{C}$ ), makes PCL an interesting substrate for tissue engineering (20-25). However, like other synthetic polymers, PCL also lacks surface wettability and functional surface groups improving the cell attachment that are essential in tissue engineering. Nowadays, concepts of hybrid scaffolds have been started to avoid such limitations and use of both natural and synthetic polymers together to combine their good properties. When natural polymers such as collagen, fibronectin, laminin, alginic acid, and chitosan are electrospun and used alone, they can exhibit properties of the extracellular matrix (26) with excellent biocompatible surface enhancing the cell adhesion $(18,19)$. However, such scaffolds are mechanically weak. In hybrid approach, the scaffold produced from synthetic polymer is used as a physical 
support and its surface is hybridized with some natural polymer enhancing cell attachment (27-29). Zhang et al. already reported the preparation of PCL/collagen scaffolds by dipping PCL ((Mw $80,000)$ ) nanofibers in collagen (type I from calf skin) solution (30). Such processes can cause clogging of the pores that are important for cell proliferation through the scaffold and also collagen dipping may not give efficient coating (30). Sometimes co-axial coating (30)/blending of PCL with collagen was also performed (31), but it may associate also some limitations. The limitations for co-axial coating/blending are that electrospinning processing parameters need to be optimized for either core (PCL; Mw 80,000)-coat solutions (collagen; type I) or co-polymer (PCL; Mw 80,000/collagen; type I) solution which might not be possible always and it may affect fiber morphology. Also, this will use more amount of collagen solution which is costly, not economical, and also mechanical strength of synthetic polymers; PCL may be compromised. Some researchers incorporated silver $(\mathrm{Ag})$ or titanium dioxide $\left(\mathrm{TiO}_{2}\right)$ nanoparticles of average diameter $21 \mathrm{~nm}$ in the nanofibrous-based scaffolds which were used in tissue engineering for some specific applications like antimicrobial or UV protection (32-36). These structures are also referred as hybrid materials or nanocomposites. When using nanoparticles as a part of the nanofiber structure, it is necessary to investigate the biocompatibility of the resulting nanocomposites and their influence on cell attachment and growth. So it is very clear that scaffoldssurface chemical properties can regulate cell activities like cell adhesion and migration over the scaffold whereas biocompatibility is also governed by structural unit/building block of scaffold.

Thus, it is important to investigate how surface chemistry and structural unit of hybrid/composite scaffold can influence the cell transplantation process towards generation of new tissue or organ (37-39).

In this work, two different types of hybrid scaffolds over PCL-NF were prepared. These are collagen-coated PCL nanofibers (Col-c-PCL) and titanium dioxide-incorporated PCL $\left(\mathrm{TiO}_{2}\right.$-i-PCL). These were investigated for surface and structural biocompatibility using fibroblasts, respectively. The presence of electrospun collagen mesh by separate electrospinning over PCL nanofibers (Col-c-PCL) changed surface property like wettability, surface chemistry of PCLNF. Incorporated antibacterial $\mathrm{TiO}_{2}$ nanoparticles have been investigated here to check their biocompatibility and how they influence cell attachment and growth over PCL composite $\left(\mathrm{TiO}_{2}\right.$-i-PCL). MTT assay and cell adhesion assays were carried out for all scaffolds (PCL-NF, Col-c-PCL, TiO 2 -i-PCL) to check biocompatibility towards tissue engineering. Detailed physicochemical investigations (scanning electron microscopy (SEM), Fourier transform IR spectroscopy (FTIR), contact angle, tensile strength, X-ray photoelectron spectroscopy (XPS), energy dispersion X-ray spectroscopy (EDX)) had been done to study morphology, interaction between polymer-polymer and polymer-nanoparticle, hydrophilicity, mechanical strength, and surface chemistry of these scaffolds.

\section{MATERIALS AND METHODS}

\section{Materials}

Reconstituted type I collagen of bovine skin was obtained from Central Leather Research Institute, Adyar, Chennai. PCL (Mw 80,000) was obtained from Sigma Aldrich, USA.
Glacial acetic acid, chloroform, and methanol in analytical grade were obtained from SRL, Mumbai. $\mathrm{TiO}_{2}$ nanopowder of $20-\mathrm{nm}$ size range was purchased from Sigma Aldrich.

\section{Methods}

\section{Sample Preparation and Electrospinning}

Different amounts of PCL $(8,11$ and $13 \% w / v)$ were dissolved in $3: 1 v / v$ chloroform/methanol mixture for obtaining PCL electrospinning solution. At first, weight amount of PCL was added in the required solvent and stirred for $2 \mathrm{~h}$. Then the mixture was sonicated for $15 \mathrm{~min}$ and again stirred for another $12 \mathrm{~h}$. Before electrospinning, solution was sonicated for $15 \mathrm{~min}$ and kept aside for another $30 \mathrm{~min}$ to remove all bubbles from the solution. The electrospinning apparatus (Holmarc, India) consisted of a 5-ml syringe with 0.84-mm internal diameter ID of a blunt end needle and integrated with a grounded electrode. The needle-tocollector distance was maintained at $12 \mathrm{~cm}$. The applied voltages were 10 and $12 \mathrm{kV}$. The solution was fed at the rate of $2 \mathrm{ml} / \mathrm{h}$ and flow rate was precisely controlled by a syringe pumping system. Thin aluminum sheet attached over the fixed collector was used to collect fibers. The electrospinning was carried out at ambient temperature and pressure to produce dry, thin scaffolds in electrospinning. Thus, PCL-NF was obtained by electrospinning method.

The $\mathrm{TiO}_{2}$-i-PCL composite was prepared by adding $\mathrm{TiO}_{2}$ nanoparticles slowly to the PCL solution under continuous stirring, and then the solution was electrospun using the same electrospinning conditions as described above. Thus $\mathrm{TiO}_{2}$-iPCL was obtained. The PCL-NF and $\mathrm{TiO}_{2}$-i-PCL were dried under vacuum at room temperature for $48 \mathrm{~h}$.

Next, to get Col-c-PCL, collagen was used for coating of PCL-NF. PCL nanofibers will be abbreviated as PCL-NF. Collagen solution was prepared by dissolving in TFE $(80 \mathrm{mg} /$ $\mathrm{ml})$.

Then, Col-c-PCL was prepared by following the method in Fig. 1.

\section{SEM Study}

At first, samples were prepared by sectioning in specific length and width for obtaining SEM images. Samples were coated by a platinum layer using a JEOL JFC 1600 Autofine coater. The images were obtained at $20 \mathrm{kV}$ and then analyzed by software Digimizer ${ }^{\circledR}$ in order to calculate the fiber diameter.

\section{EDX Study}

EDX analysis of $\mathrm{TiO}_{2}$-i-PCL was performed using the field-emission scanning electron microscope (FE-SEM) MIRA, manufactured by Tescan and equipped with the EDX add-on (Oxford Instruments). The Au coating with a thickness of $10 \mathrm{~nm}$ was deposited by RF magnetron sputtering prior to the imaging in order to compensate for a charging. The electrons were accelerated by a $15-\mathrm{kV}$ high voltage, and the working distance was fixed at $15 \mathrm{~mm}$ in order to minimize the charging effect and to improve the resolution. The 


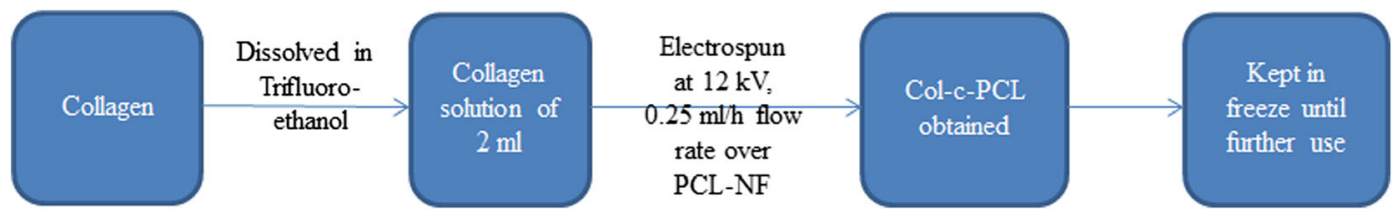

Fig. 1. Preparation of Col-c-PCL

quantification of the elemental composition was determined in the field of $43 \times 43 \mu \mathrm{m}$ by the in-built software Aztec.

\section{FTIR Study}

FTIR spectroscopic analysis of electrospun material was made using spectrum one (PerkinElmer, USA model). Attenuated total reflectance-FTIR (ATR-FTIR) spectra of PCL and Col-c-PCL and $\mathrm{TiO}_{2}$-i-PCL were recorded in the wavenumber range of $4000-600 / \mathrm{cm}$ at room conditions in ATR mode using 500 scans. The sample was kept on the diamond ATR top plate and through pressure arm; pressure was loaded on sample/crystal area before collecting FTIR spectra. PerkinElmer's revolutionary Spectrum ${ }^{\text {TM }}$ FT-IR software helped to collect spectra.

\section{XPS Study}

XPS for a surface $(2-3 \mathrm{~nm})$ chemical characterization of nanofibers was carried out using an Omicron X-ray source (DAR400, output power $270 \mathrm{~W}$ ) and an electron spectrometer (EA125) attached to a custom-built ultra-high vacuum system. The quantitative composition was determined from detailed spectra taken at the pass energy of $25 \mathrm{eV}$ and the electron takeoff angle $50^{\circ}$. The maximum lateral dimension of the analyzed area was $1.5 \mathrm{~mm}$. The quantification was carried out using XPS MultiQuant software.

\section{Contact Angle Measurement}

Contact angle measurement was done using contact angle meter (Holmarc Optomechatronics). For determination of hydrophilicity of samples, at first, the sample was kept on the flat bench of the instrument and then water droplet with size of $0.5 \mu \mathrm{l}$ was set to fall on the sample. The contact angle was measured by a video contact angle system after $10 \mathrm{~min}$ of stabilizing, and five samples were measured for each test.

\section{Mechanical Properties}

For measuring tensile strength of the electrospun nanofibers, universal tensile machine (UTM) INSTRON 1408 was used and the measurement was carried out by following ASTM D 882 standard. Tensile testing was carried out using $500 \mathrm{~N}$ load cells at a speed of $1 \mathrm{~mm} / \mathrm{min}$ onto the specimen. The samples were prepared with width of $5 \mathrm{~mm}$, gauge length of $20 \mathrm{~mm}$, and thickness of $0.2 \mathrm{~mm}$. All the experiments were done for three samples for each specimen.

\section{MTT Assay}

For cell cultivation tests, L929 fibroblast cell lines were purchased from NCCS Pune. The cell line was maintained in Dulbecco's modified Eagle's media (HIMEDIA) supplemented with $10 \%$ FBS (Invitrogen) and grown to confluency at $37^{\circ} \mathrm{C}$ in $5 \% \mathrm{CO}_{2}$ (NBS, Eppendorf, Germany) in a humidified atmosphere in a $\mathrm{CO}_{2}$ incubator.

For MTT assay, the cells were trypsinized (500 $\mu$ l of $0.025 \%$ trypsin in PBS/0.5 mM EDTA solution (HIMEDIA)) for $2 \mathrm{~min}$ and then passaged to $\mathrm{T}$ flasks in complete aseptic conditions. Samples of $1 \mathrm{~cm}^{2}$ from different formulations were sterilized and immersed in cell-free media for $24 \mathrm{~h}$. Next day, trypsinzed cells were added on to the surface of nanofibers and allowed to grow for $24 \mathrm{~h}$ followed by MTT assay. Optical density (OD) was read at $540 \mathrm{~nm}$ using DMSO as blank using an ELISA reader (LISASCAN, Erba). Since reduction of MTT can only occur in metabolically active cells, the level of activity is a measure of the viability of the cells.

\section{Cell Adhesion Study}

At first, samples were cleaned ultrasonically and freeze dried in a lyophilizer. Then samples were sterilized using ethylene oxide (ETO) and stored aseptically. After overnight incubation in serum-supplemented DMEM cell culture media at $37^{\circ} \mathrm{C}$ in a $\mathrm{CO}_{2}$ incubator, freshly trypsinized L929 cells were seeded on the surface of the scaffold and permitted to attach for $30 \mathrm{~min}$ followed by media supplementation. The cells were allowed to grow for $72 \mathrm{~h}$. Cell adhesion was determined using acridine orange staining. After removing excess stain, morphology was assessed by fluorescent and phase contrast microscopy.

Cell adhesion study was carried out by following the method in Fig. 2.

\section{Data and Statistical Analysis}

Results are presented as mean \pm standard deviation (SD). Statistical comparisons were made at significance level of $p<0.05$ using MS Excel software.

\section{RESULTS AND DISCUSSION}

\section{SEM Study}

Electrospinning is a way to generate fibrous scaffold from different synthetic and natural polymers. Voltage is one of the most important processing parameters to be set up for electrospinning. Electrostatic stress which pulled polymer as fiber from its solution will be obtained from electrospinning voltage. Fibers from charged polymer solution only will be obtained if voltage at threshold value is applied. This threshold voltage value differs for different polymer solutions. It depends on polymer concentration, viscosity of solution, humidity, temperature, etc. Fiber diameter and fiber morphology also can be affected by electrospinning voltage. Many research papers have shown fiber diameter increased 


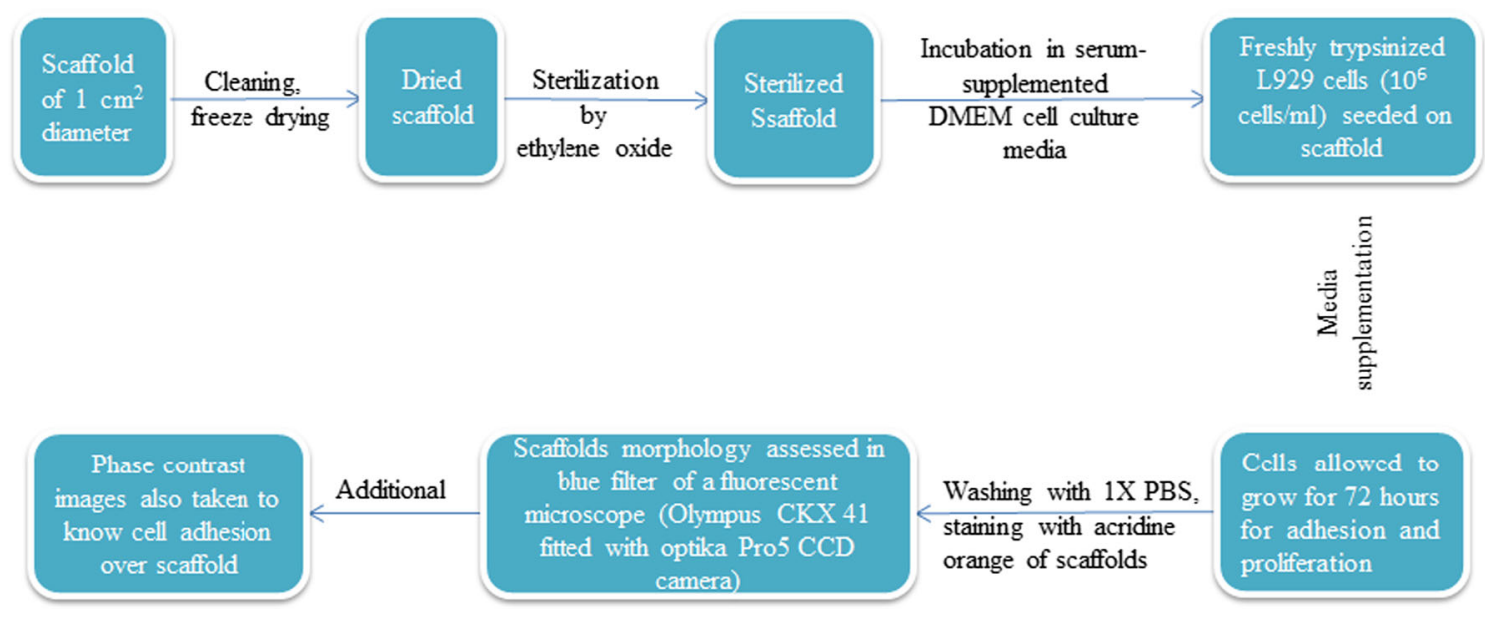

Fig. 2. Description of Cell adhesion study

with increased voltage $(40,41)$ and many papers have reported reverse $(42,43)$.

According to SEM, the fiber diameter for PCL at $11 \%$ concentration tended to decrease slightly with increased voltage from 10 to $12 \mathrm{kV}$. It can be explained by an electrostatic repulsive force on jet narrowing the fibers. Similar effects were observed when $13 \%$ PCL concentration was used (images are not shown). So the fiber diameter decreased for both 11 and $13 \%$ PCL concentrations with the increase of voltage. The ribbon-shaped nanofibers were observed at lower voltage $(10 \mathrm{kV})$, whereas continuous nanofibers were obtained with increased voltage (Fig. 3a, b, respectively). Such effect can be explained by the fact that low voltage is not enough to stretch the polymer as continuous fiber from these higher polymer concentration solutions and bending instabilities occur (43). So polymer concentration should be optimized for obtaining nanofibers in electrospinning process. Here, PCL concentration was lowered to $8 \%$ and then electrospinning was performed at $10 \mathrm{kV}$ voltages. The continuous nanofibers with diameter distribution from 2.0 to $0.4 \mu \mathrm{m}$ were produced without beads evidenced by SEM (Fig. 3c). Hence, $10-\mathrm{kV}$ voltages were adequate to produce a continuous nanofiber from a lower polymer concentration. For carrying out further studies, PCL-NF obtained from $8 \%$ PCL at $10 \mathrm{kV}$ was used for collagen coating and also for $\mathrm{TiO}_{2}$ incorporation. Figure $3 \mathrm{~d}$ represents Col-c-PCL. Here, some portions of the prepared fibers looked thicker as we obtained the fibers from nano to micro range.

\section{EDX Spectra and XPS Analysis}

The addition of the $\mathrm{TiO}_{2}$ into the PCL solution led to electrospun nanofibers with sufficient amount of the embedded $\mathrm{TiO}_{2}$. Even addition of 1 wt. $\%$ of $\mathrm{TiO}_{2}$ into the PCL solution led to the incorporation of the $\sim 10 \mathrm{wt} \%$ of $\mathrm{Ti}$, as EDX analyses revealed (Fig. 4a, b). As shown in Fig. 4a, b, the

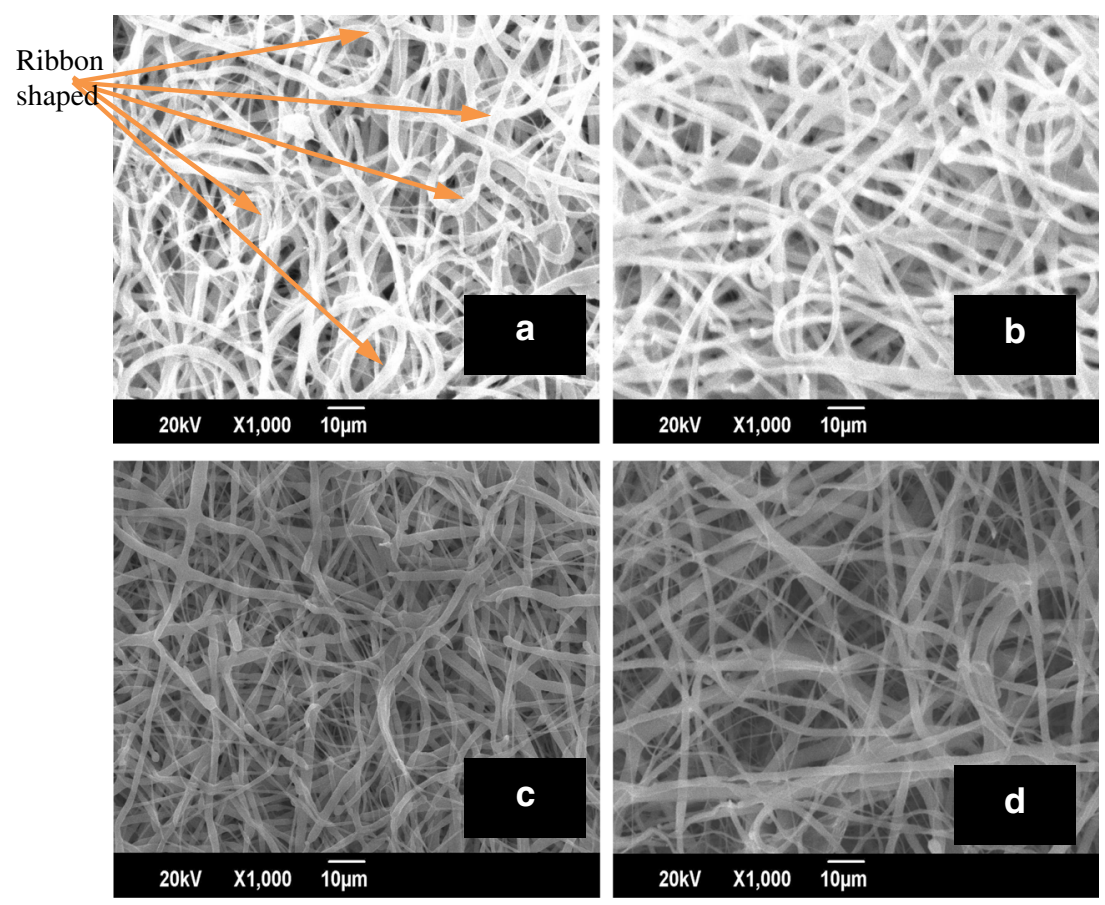

Fig. 3. SEM images of nanofibers. a $11 \%$ PCL, PCL-NF at $10 \mathrm{kV}$; b $11 \%$ PCL, PCL-NF at $12 \mathrm{kV}$; c 8\% PCL, PCL-NF at $10 \mathrm{kV}$; and d Col-c-PCL 
distribution of $\mathrm{Ti}$ is quite homogenous along the nanofibers. However, some clusters of $\mathrm{TiO}_{2}$ were observed in Fig. 4a. To incorporate $\mathrm{TiO}_{2}$ nanoparticle in PCL-NF, the nanoparticle was dispersed in the PCL solution. So during solution preparation, some titania may bind to PCL and clusters of titania of varying sizes are observed adhering to fibers (44). It is difficult to conclude from EDX if the $\mathrm{TiO}_{2}$ is embedded inside the nanofibers or simply stuck to the surface. Thus, the surfacesensitive XPS analyses were performed on the same sample, and the survey scan is depicted in Fig. 4c. The XPS analyses revealed the presence of carbon and oxygen with the $\mathrm{O} / \mathrm{C}$ ratio of 0.28 . No even traces of Ti were visible in the spectra in spite of very high relative sensitivity of this element. Therefore, the Ti revealed by the EDX cartography is homogenously embedded in the bulk of nanofibers and does not represent any heterogeneous nanoparticles trapped between the nanofibers.

\section{Contact Angle Measurements}

The contact angle value of PCL-NF was about $88^{\circ}$ (Fig. 5). The contact angle values (45) were lower for collagen-coated PCL-NF due to the hydrophilicity of the collagen. When liquid was dropped over these nanofibrous scaffold, the convex shape of the drop became more flat and measured values were seen $40^{\circ}$ for Col-c-PCL after $10 \mathrm{~min}$. $\mathrm{TiO}_{2}$-i-PCL nanofibrous scaffold also showed decrement of contact angles but in a very small extent. The value decreased to $80^{\circ}$. These contact angle determination was performed for three specimens in each sample.
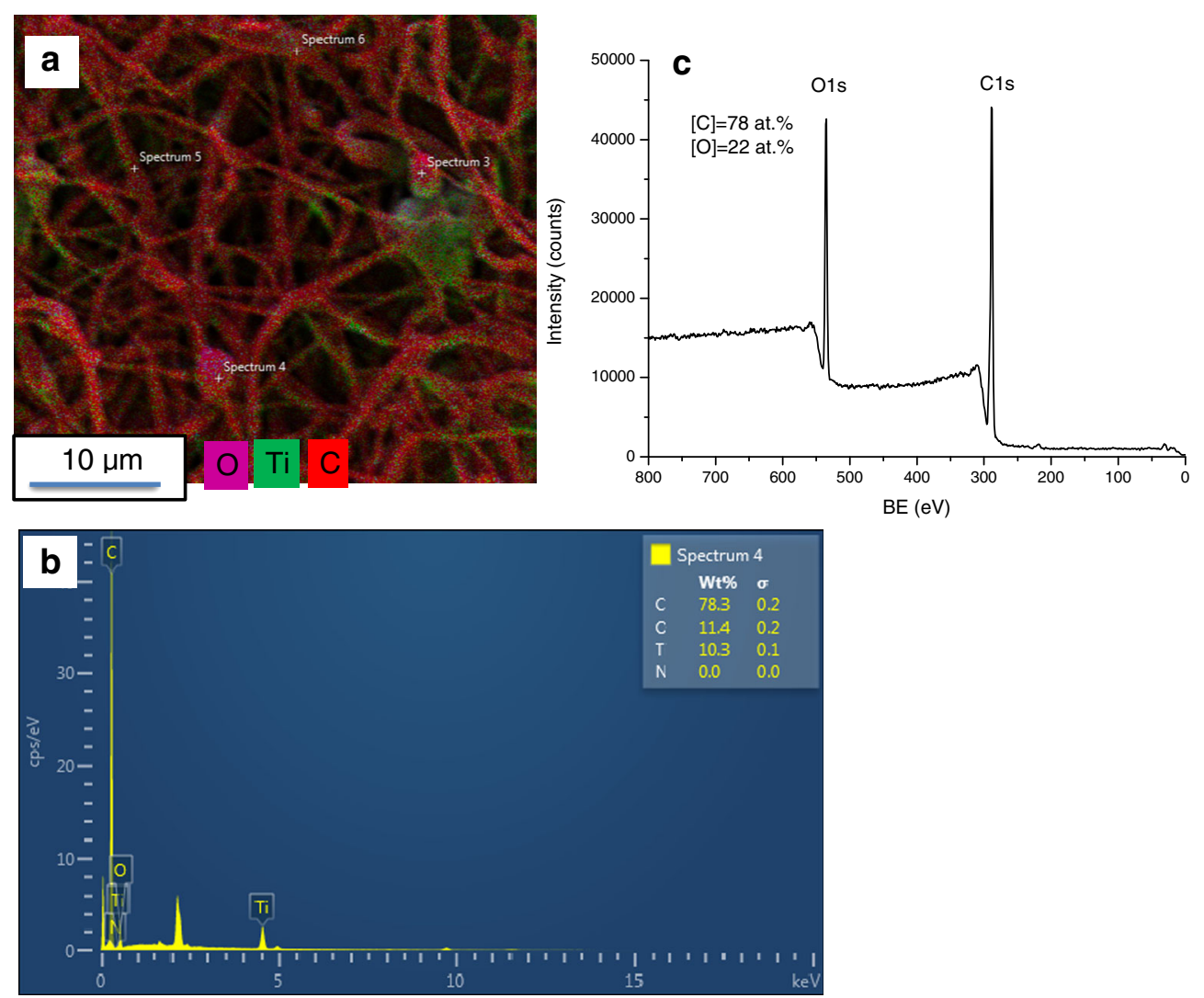

Fig. 4. Effects of $\mathrm{TiO}_{2}$ addition. a EDX mapping of $\mathrm{TiO}_{2}-\mathrm{i}-\mathrm{PCL}$. b The representative EDX spectrum of $\mathrm{TiO}_{2}$-i-PCL. $\mathbf{c}$ XPS survey scan of TiO ${ }^{-}$ i-PCL

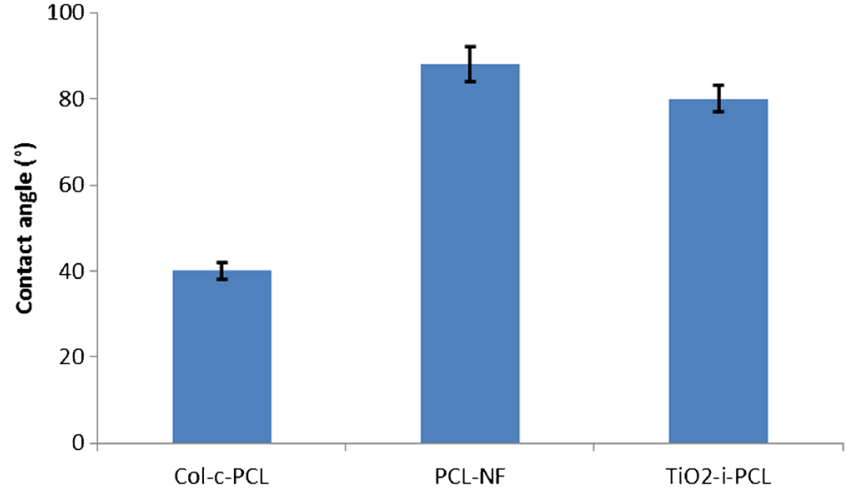

Fig. 5. Contact angle values with standard deviations for scaffolds

Generally, contact angle value is used to know whether matrix/nanofibrous mat used is hydrophilic or hydrophobic. Contact angle values of 0 to $30^{\circ}$ present hydrophilic surface, 30 to $90^{\circ}$ contact angle value present less hydrophilic surface, and more than $90^{\circ}$ values present hydrophobic surface. So we can see that PCL matrix alone produces hydrophobic surface. But presence of collagen mess or $\mathrm{TiO}_{2}$ incorporation enhanced its hydrophilcity. Amine as a fuctional group is present in collagen structure in large numbers and this enhanced hydrophilicity of Col-c-PCL might be attributed to this functional group. As $\mathrm{TiO}_{2}$ nanoparticles were well dispersed throughout the matrix and also enhanced surface to volume ratio of electrospun matrix, they increased hydrophilicity of $\mathrm{TiO}_{2}$-i-PCL matrix at some extent. Many other research groups have shown that blending of polymers or presence of 

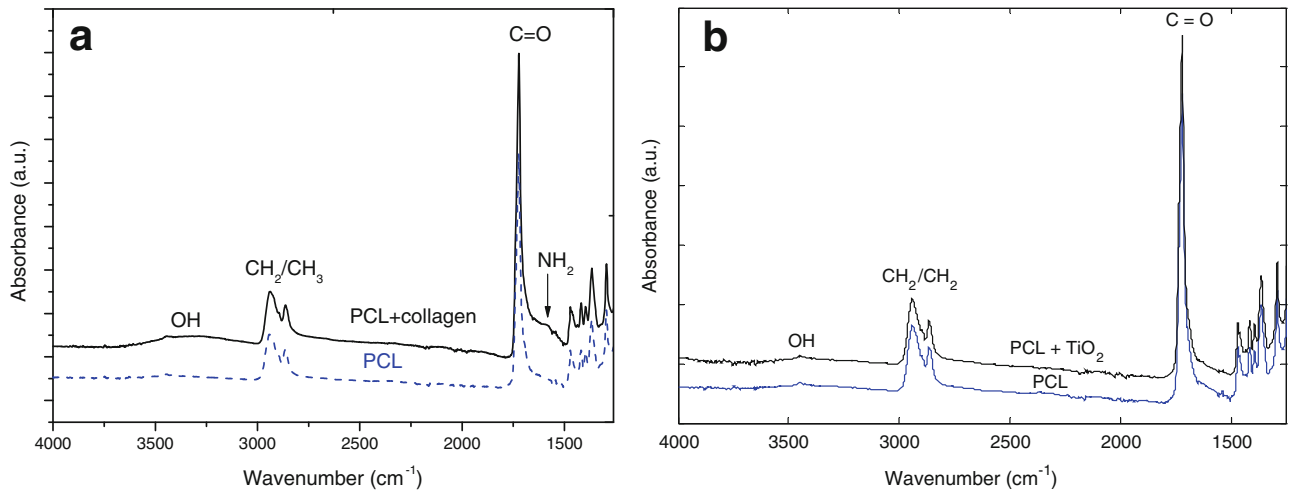

Fig. 6. ATR-FTIR spectra of a Col-c-PCL and PCL-NF and $\mathbf{b} \mathrm{TiO}_{2}-\mathrm{i}-\mathrm{PCL}$ and PCL-NF

nanoparticle may modify surface properties of nanofibrous matrix. Shalumona et al. (2011) (46) showed also enhancement of hydrophilicity of PCL nanofibrous matrix by blending PCL with chitosan. Similar work carried out by Zhang et al. (2005) (47) showed blending of gelatin with PCL improved its hydrophilicity. Pant et al. (48) used $\mathrm{TiO}_{2}$ nanoparticles in nylon-6 nanofibrous membrane, and hydrophilicity of this matrix was improved significantly. Enhanced hydrophilicity for scaffold used in tissue engineering is desirable for initial cell adhesion and cell migration. Hydrophobic surface shows lower cell adhesion (49).

\section{FTIR Data}

FTIR analyses of PCL-NF and Col-c-PCL revealed peaks at 2991, 2900, and $2878 / \mathrm{cm}$ for $\mathrm{CH}_{2}$ vibrations. The intense sharp peak at $1720 \mathrm{~cm}$ for $\mathrm{C}=\mathrm{O}$ vibrations; $\mathrm{CH}_{2}$ bending vibrations at around 1490,1450 , and $1362 \mathrm{~cm}$; and COO vibrations at around 1250 were attributed to PCL structure (Fig. 6a). Then at around $1570 / \mathrm{cm}$, one peak was visible only in the Col-c-PCL and was attributed to $\mathrm{NH}$ bending vibrations of collagen. The presence of amide group in FTIR spectroscopy of Col-cPCL nanofibrous scaffolds indicates that the PCL chain was chemically attached to collagen and it may improve biocompatibility of PCL-NF scaffold in tissue engineering. From Fig. 6b, it is evident that incorporation of $\mathrm{TiO}_{2}$ was quite compatible with PCL as all the corresponding peaks of PCL were clearly observed in FTIR spectra.

\section{Mechanical Properties}

The incorporation of $\mathrm{TiO}_{2}$ has increased mechanical strength of PCL-NF, as shown in Table I. The collagen-coated PCL-NF was not used for tensile strength study due to high cost of collagen. It can be assumed that additional coating with collagen may slightly increase the tensile strength of PCL-NF, as Lee et al. reported before (28). Guo et al. has shown that use of functionalized alumina nanoparticle in polymer nanocomposite increased both modulus and tensile strength (50). The enhanced mechanical property was due to interfacial attachment of functionalized alumina nanoparticle with vinyl-ester resin. In another study, silver nanoparticles were embedded uniformly in nylon nanocomposite and enhancement of mechanical strength of nylon fibers (51) was noticed. Similar results were observed for PCL-PU nanocomposite. Use of silver nanoparticles in PCL-PU nanocomposite improved tensile strength and tensile modulus of this composite due to more fiber packing (52). So overall, use of nanoparticle has increased mechanical strength of nanocomposite. In the present study, mechanical characterization results of PCL nanocomposite are quite consistent with other reported results. It can be assumed that the mostly homogenous distribution of $\mathrm{TiO}_{2}$ nanoparticles in PCL nanofiber at lower concentration helped to distribute stress uniformly, minimized formation of stress-concentration centers, and further helped to increase interfacial area for stress transfer from the polymer matrix to the fillers. Indeed, EDX spectra confirmed that $\mathrm{TiO}_{2}$ was mostly homogenously dispersed in nanofiber structure and, therefore, it closely interacted with PCL and as a result, the mechanical strength was improved. Li et al. (53) have investigated that nanoparticles at lower percentage has strong reinforcing effects leading to production of nanofibers with increased mechanical strength. But increased concentration of nanoparticle may decrease tensile strength and modulus of composite. As concentration of nanoparticle is increased more, nanoparticles may aggregate and, as a result, effective interfacial interactive area between nanoparticle and nanofiber is decreased. So optimization of nanoparticle in a concern to mechanical property of nanocomposite is very requisite. Further exploration such as optimization of mechanical strength of PCL composite using different nanoparticle concentration will be carried out in a future study to get PCL composite scaffold as a three-dimensional fibrous skin tissue engineered construct providing desirable mechanical property.

Table I. Mechanical Strength of Nanofibers

\begin{tabular}{lccrr}
\hline Formulation code & Ultimate MPa & Break stress MPa & Yield stress MPa & Modulus MPa \\
\hline PCL-NF & $1.343 \pm 0.01$ & $0.73 \pm 0.06$ & $1.273 \pm 0.04$ & $3.80 \pm 0.02$ \\
$\mathrm{TiO}_{2}$ - - -PCL & $1.531 \pm 0.003$ & $1.507 \pm 0.01$ & $1.390 \pm 0.01$ & $4.103 \pm 0.11$ \\
\hline
\end{tabular}

$P C L-N F$ poly ( $\varepsilon$-caprolactone) (PCL) nanofibers, $\mathrm{TiO}_{2} i$ - $P C L$ titanium dioxide-incorporated PCL 


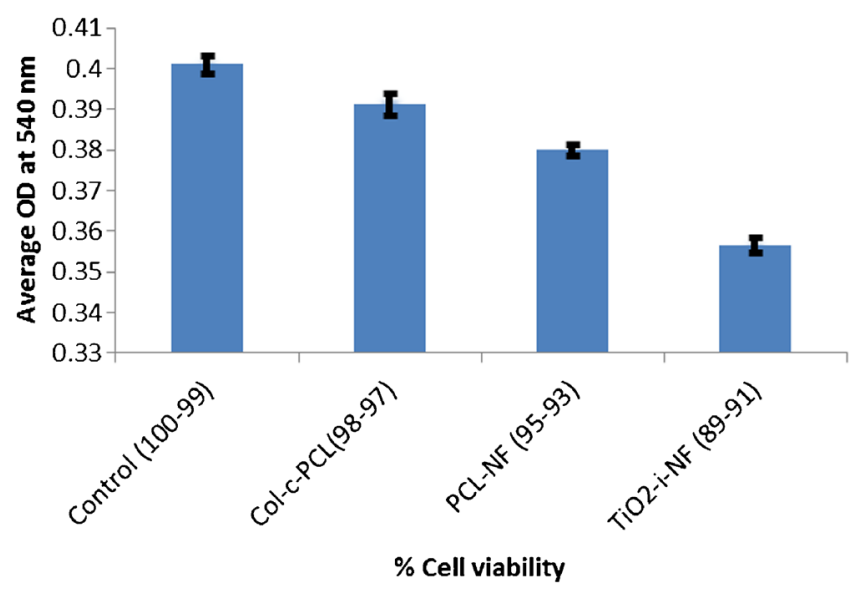

Fig. 7. MTT assay of nanofibers

\section{MTT Assay}

MTT assays had shown cell viability in different types of PCL nanofibrous matrix. The result is shown in Fig. 7. Cells were allowed to grow in different polymer nanofibrous matrix solutions for $24 \mathrm{~h}$ and then by absorbance values, \% viability of cells had been estimated. It was clear that cell metabolism activity over electrospun nanofibers established cytocompatibility. Degradation products released from the scaffold were non-toxic and did not hamper cell growth. However, slight reduction of \% viability in $\mathrm{TiO}_{2}$-i-PCL sample was observed due to presence of $\mathrm{TiO}_{2}$ nanoparticles. However, still approximately $90 \%$ of cells were viable over the matrix which was good for assuming it as appropriate scaffold for tissue engineering application. To get more clear ideas, cell viability over PCL-NF matrix containing different percentage ratios of these antibacterial nanoparticles would be performed in the next possible study. Col-c-PCL promotes more cell growth than PCL-NF, because coating of collagen over any synthetic polymer nanofibers could enhance their biocompatibility (19). In this study, the \% viability of cells in the presence of different electrospun matrixes was compared and calculated as the percentage relative to the untreated control cells (cells were not added in any nanofibrous matrix solution).

\section{Cell Adhesion Study}

Fluorescence images and phase contrast images were taken to see the attachment of L929 fibroblast cells over the scaffold. Additionally, these tests helped to know whether there was any change in the morphology of cells due to contact with the different types of nanofibrous scaffold.

Initially, cell adhesion and spreading over the scaffold would be considered as essential step for cell growth required for wound healing and restoration of the tissues. To investigate fibroblasts adhesion and spreading on the surface of scaffold, fluorescence and phase microscopy images were acquired. All images (Figs. 8 and 9) clearly proved that normal morphology of cells was maintained even after 3 days for different types of nanofibrous scaffold. Spindle-like shapes are for live cells and rounded cell are for dead cells. Hence, the initial requirements for being an essential scaffold (cell morphology maintenance, attachment and spreading of cells) were fulfilled. However, higher numbers of dead cells have been observed on $\mathrm{TiO}_{2}$-i-PCL scaffold due to nanoparticle toxicity.

Fluorescence images also proved that cells are adhering through nanofibers. Live cells were shown by green nucleus, whereas the dead cells were presented with an orange color. Figures 8 and 9 showed presence and adhesion of higher number of cells over the Col-c-PCL nanofibrous scaffold and higher numbers of dead cells were seen over $\mathrm{TiO}_{2}$-i-PCL nanofibers scaffold. It is clear that presence of collagen would
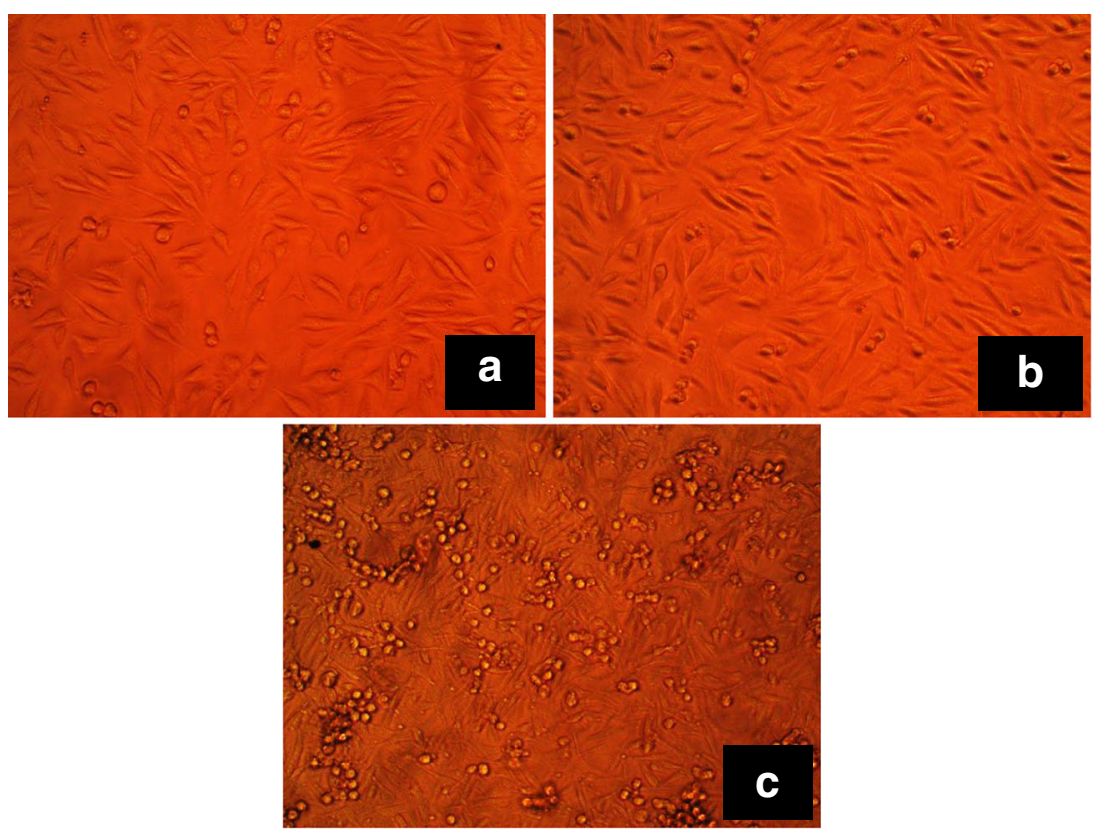

Fig. 8. Phase contrast images for cell adhesion study over a PCL-NF, b Col-c-PCL, and $\mathbf{c} \mathrm{TiO}_{2}-\mathrm{i}-\mathrm{PCL}$ 

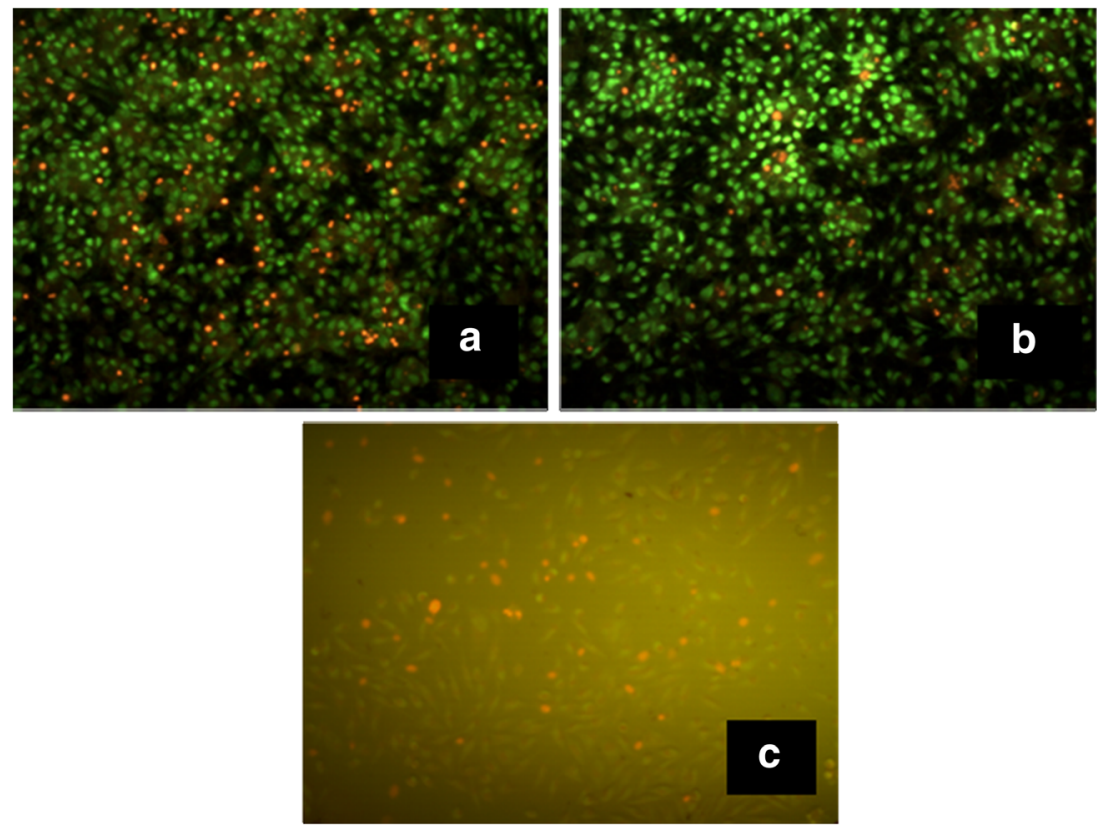

Fig. 9. Fluorescence images for cell adhesion study over a PCL-NF, b Col-c-PCL, and $\mathbf{c} \mathrm{TiO}_{2}$-i-PCL

mimic as extracellular matrix and enhanced the cell adhesion. However, optimized $\mathrm{TiO}_{2}$ nanoparticle concentration and collagen coating will help to engineer PCL-based scaffold favoring wound tissue formation with antimicrobial property.

Zhang et al. (30) showed in their study that co-axial blending of collagen over PCL mimicked as ECM due to widespread presence of biological samples like collagen and influenced cell-scaffold interaction. This kind of scaffold showed significant cell migration $(31.8 \%$ in 6 days) than the scaffold which was hybridized by dipping PCL nanofibers in collagen solution $(21.0 \%$ in 6 days). But, it was certain that inert PCL needs coatings of bioactive samples. So our approach towards coating of PCL by biologically active sample (collagen) via electrospinning was beneficial for this kind of scaffold of skin tissue engineering. From Fig. 3, scaffold confirmed porous structure which assisted transportation of nutrition and metabolic waste, thus regulates cell-scaffold interaction. Though porosity was not measured here, we will try to perform in a future study.

\section{CONCLUSION}

PCL nanofibers with collagen coating and entrapped $\mathrm{TiO}_{2}$ nanoparticles were successfully synthesized. Polymer concentrations and working voltages in electrospinning technique had a significant effect on the fiber morphology. The hydrophilicity of the electrospun nanofibers could be significantly enhanced by collagen coating and slight modification was also possible with $\mathrm{TiO}_{2}$ insertion. According to EDX spectra, the $\mathrm{TiO}_{2}$ homogenously distributed in the nanofibrous mesh. No traces of Ti were visible in the XPS spectra, and therefore, all $\mathrm{TiO}_{2}$ that was revealed by EDX was embedded inside the nanofibers. The incorporation of the $\mathrm{TiO}_{2}$ nanoparticles had increased mechanical strength of the nanocomposite, but the presence of this material slightly decreases the viability of cells. The MTT assay and the cell adhesion study indicated these nanocomposites as a suitable biomaterial for skin tissue engineering, though the optimization of nanoparticle concentration needs to be further addressed. Further investigations will be carried out in a future study to get maximum antibacterial property from $\mathrm{TiO}_{2}$ with minimization of its toxic property.

\section{ACKNOWLEDGMENTS}

The research has been sponsored by the University Grants Commission, India, under the UGC Dr. D. S. Kothari postdoctoral fellowship scheme under the Application No. EN/12-13/0003. This research has been financially supported by the Ministry of Education, Youth and Sports of the Czech Republic under the project CEITEC 2020 (LQ1601) and COST CZ project LD15150 financed by the Ministry of Education of the Czech Republic. One of us A.M. acknowledges the BioFibPlas project No. 3SGA5652 financed from the SoMoPro II Programme that has acquired a financial support from the People Programme (Marie Curie Action) of the Seventh Framework Programme of EU according to the REA Grant Agreement No. 291782. This publication reflects only the author's views and the Union is not liable for any use that may be made of the information contained therein. Authors thanks Dr. Alexander Bannov for the carrying the SEM - EDX measurements. Cell culture work was carried out in Biogenix Research Centre, Kerala, India.

\section{REFERENCES}

1. Chen G, Ushida T, Tateishi T. Scaffold design for tissue engineering. Macromol Biosci. 2002;2:67-77.

2. Yang S, Leong KF, Du Z, Chua CK. The design of scaffolds for use in tissue engineering. Part I. Traditional factors. Tissue Eng. 2001;7(6):679-89. 
3. Hollister SJ. Porous scaffold design for tissue engineering. Nat Mater. 2005;4(7):518-24.

4. Patrícia BM, Gabriela AS, Rui LR. Natural-origin polymers as carriers and scaffolds for biomolecules and cell delivery in tissue engineering applications. Adv Drug Deliv Rev. 2007;59:207-33.

5. Podporska-Carroll J, Ip JWY, Gogolewski S. Biodegradable poly (ester urethane) urea scaffolds for tissue engineering: interaction with osteoblast-like MG-63 cells. Acta Biomater. 2014;10(6):2781-91.

6. Formhals A. US Patent No. (1934)1,975,504.

7. Haghi AK. Electrospun nanofiber process control. Cell Chem Technol. 2010;44(9):343-52.

8. Li D, Xia Y. Electrospinning of nanofibers: reinventing the wheel? Adv Mater. 2004;16(14):1151-70.

9. Huang W, Zou T, Li S, Jing J, Xia X, Liu X. Drug-loaded zein nanofibers prepared using a modified coaxial electrospinning process. AAPS PharmSciTech. 2013;14(2):675-81.

10. Ju YM, San Choi J, Atala A, Yoo JJ, Lee SJ. Bilayered scaffold for engineering cellularized blood vessels. Biomaterials. 2010;31(15):4313-21.

11. Samprasit W, Rojanarata T, Akkaramongkolporn P, Ngawhirunpat T, Kaomongkolgit R, Opanasopit P. Fabrication and In Vitro/In Vivo Performance of Mucoadhesive Electrospun Nanofiber Mats Containing $\alpha$-Mangostin. AAPS PharmSciTech, 2015;1-13.

12. You Y, Min BM, Lee SJ, Lee TS, Park WH. In vitro degradation behavior of electrospun polyglycolide, polylactide, and poly (lactide-co-glycolide). J Appl Polym Sci. 2005;95:193-200.

13. You Y, Youk JH, Lee SW, Min BM, Lee SJ, Park WH. Preparation of porous ultrafine PGA fibers via selective dissolution of electrospun PGA/PLA blend fibers. Mater Lett. 2006;60(6):75760.

14. Asawahame C, Sutjarittangtham K, Eitssayeam S, Tragoolpua Y, Sirithunyalug B, Sirithunyalug J. Antibacterial activity and inhibition of adherence of Streptococcus mutans by propolis electrospun fibers. AAPS PharmSciTech. 2015;16(1):82-191.

15. Kim K, Lu YK, Chang C, Fang D, Hsiao BS, Chu B, et al. Incorporation and controlled release of a hydrophilic antibiotic using poly (lactide-co-glycolide)-based electrospun nanofibrous scaffolds. J Controlled Release. 2004;98(1):47-56.

16. Ghosal K, Thomas S, Kalarikkal N, Gnanamani A. Collagen coated electrospun polycaprolactone (PCL) with titanium dioxide $\left(\mathrm{TiO}_{2}\right)$ from an environmentally benign solvent: preliminary physico-chemical studies for skin substitute. J Polym Res. 2014;21(5):1-5.

17. Yao C, Li X, Neoh KG, Shi Z, Kang ET. Surface modification and antibacterial activity of electrospun polyurethane fibrous membranes with quaternary ammonium moieties. J Membr Sci. 2008;320(1):259-67.

18. Nicknejad ET, Ghoreishi SM, Habibi N. Electrospinning of Cross-Linked Magnetic Chitosan Nanofibers for Protein Release. AAPS PharmSciTech. 2015:1-7.

19. Subramanian G, Bialorucki C, Yildirim-ayan E. Nanofibrous yet injectable polycaprolactone-collagen bone tissue scaffold with osteoprogenitor cells and controlled release of bone morphogenetic protein-2. Mater Sci Eng C. 2015;51:16-27.

20. Gautam S, Chou CF, Dinda AK, Potdar PD, Mishra NC. Surface modification of nanofibrous polycaprolactone/gelatin composite scaffold by collagen type I grafting for skin tissue engineering. Mater Sci Eng C. 2014;34:402-9.

21. Ko YM, Choi DY, Jung SC, Kim BH. Characteristics of plasma treated electrospun polycaprolactone (PCL) nanofiber scaffold for bone tissue engineering. J Nanosci Nanotech. 2015;15:192-5.

22. Chong LH, Lim MM, Sultana N. Polycaprolactone (PCL)/gelatin $(\mathrm{Ge})$-based electrospun nanofibers for tissue engineering and drug delivery application. Appl Mech Mater. 2014;554:57-61.

23. Lou T, Leung M, Wang X, Chang JYF, Tsao CT, Sham JGC, et al. Bi-layer scaffold of chitosan/PCL-nanofibrous mat and PLLAmicroporous disc for skin tissue engineering. J Biomed Nanotechnol. 2014;10:1105-13.

24. Du Y, Xiaofeng C, Koh YH, Lei BO. Facilely fabricating PCL nanofibrous scaffolds with hierarchical pore structure for tissue engineering. Mater Lett. 2014;122:62-5.

25. Gomes SR, Rodrigues G, Martins GG, Roberto MA, Mafra M, Henriques CMR. In vitro and in vivo evaluation of electrospun nanofibers of PCL, chitosan and gelatin: a comparative study. Mater Sci Eng C. 2015;46:348-58.

26. Chandika P, Ko SC, Oh GW, Heo SY, Nguyen VT, Jeon YJ, et al. Fish collagen/alginate/chitooligosaccharides integrated scaffold for skin tissue regeneration application. Int J Bio Macromol. 2015;81:504-13.

27. Dunn MG, Bellincampi LD, Tria AJ, Zawadsky JP. Preliminary development of a collagen-PLA composite for ACL reconstruction. J Appl Polym Sci. 1997;63:1423-8.

28. Lee JJ, Yu HS, Hong SJ, Jeong I, Jang JH, Kim HW. Nanofibrous membrane of collagen-polycaprolactone for cell growth and tissue regeneration. J Mater Sci Mater Med. 2009;20:1927-35. doi:10.1007/s10856-009-3743-z.

29. Chen G, Ushida T, Tetsuya T. Hybrid biomaterials for tissue engineering: a preparative method for PLA or PLGA-collagen hybrid sponges. Adv Mater. 2000;12:455-7.

30. Zhang YZ, Venugopal J, Huang ZM, Lim CT, Ramakrishna S. Characterization of the surface biocompatibility of the electrospun PCL-collagen nanofibers using fibroblasts. Biomacromolecules. 2005;6(5):2583-9.

31. Chakrapani VY, Gnanamani A, Giridev VR, Madhusoothanan M, Sekaran G. Electrospinning of type I collagen and PCL nanofibers using acetic acid. J Appl Polym Sci. 2012;125(4):3221-7.

32. Kamyar SM. Green synthesis of silver/montmorillonite/chitosan bionanocomposites using the UV irradiation method and evaluation of antibacterial activity. Int J Nanomedicine. 2010;5:875-87.

33. Zhuanga XC. Electrospun chitosan/gelatin nanofibers containing silver nanoparticles. Carbohydr Polym. 2010;82:524-7.

34. Jao WC, Yang MC, Lin CH, Hsu CC. Fabrication and characterization of electrospun silk fibroin/ $/ \mathrm{TiO}_{2}$ nanofibrous mats for wound dressings. Polymer Adv Tech. 2012;23(7):1066-76.

35. Ghosal K, Latha MS, Thomas S. Poly (ester amides)(PEAs) — scaffold for tissue engineering applications. Eur Polym J. 2014;60:58-68.

36. Reddy PR, Varaprasad K, Sadiku R, Ramam K, Reddy GVS, Raju KM, et al. Development of gelatin based inorganic nanocomposite hydrogels for inactivation of bacteria. J Inorg Organomet Polym Mater. 2013;23(5):1054-60.

37. Boyan BD, Hummert TW, Dean DD, Schwartz Z. Role of material surfaces in regulating bone and cartilage cell response. Biomaterials. 1996;17:137-46.

38. Sanders JE, Stiles CE, Hayes CL. Tissue response to singlepolymer fibers of varying diameters: evaluation of fibrous encapsulation and macrophage density. J Biomed Mater Res. 2000;52:231-7.

39. Wan H, Williams RL, Doherty PJ, Williams DF. A study of cell behavior on the surfaces of multifilament materials. J Mater Sci Mater Med. 1997;8:45-51.

40. Bölgen N, Menceloğlu YZ, Acatay K, Vargel I, Pişkin E. In vitro and in vivo degradation of non-woven materials made of poly $(\varepsilon-$ caprolactone) nanofibers prepared by ectrospinning under different condition. J Biomater Sci Polym Ed. 2005;16(12):1537-55.

41. Demir MM, Gulgun MA, Menceloglu YZ, Erman B, Abramchuk SS, Makhaeva EE, et al. Palladium nanoparticles by electrospinning from poly (acrylonitrile-co-acrylic acid)-PdCl2 solutions. Relations between preparation conditions, particle size, and catalytic activity. Macromolecules. 2004;37(5):1787-92.

42. Nottelet B, Pektok E, Mandracchia D, Tille JC, Walpoth B, Gurny $\mathrm{R}$, et al. Factorial design optimization and in vivo feasibility of poly( $\varepsilon$-caprolactone)-micro- and nanofiber-based small diameter vascular grafts. J Biomed Mater Res. 2009;89A:865-75. doi:10.1002/jbm.a.32023.

43. Megelski S, Stephens JS, Chase DB, Rabolt JF. Micro-and nanostructured surface morphology on electrospun polymer fibers. Macromolecules. 2002;35(22):8456-66.

44. Bedford NM, Steckl AJ. Photocatalytic self-cleaning textile fibers by coaxial electrospinning. ACS Appl Mater Interfaces. 2010;2(8):2448-55.

45. Prabhakaran MP, Venugopal JR, Ramakrishna S. Mesenchymal stem cell differentiation to neuronal cells on electrospun nanofibrous substrates for nerve tissue engineering. Biomaterials. 2009;30(28):4996-5003.

46. Shalumon KT, Anulekha KH, Chennazhi KP, Tamura H, Nair SV, Jayakumar R. Fabrication of chitosan/poly (caprolactone) 
nanofibrous scaffold for bone and skin tissue engineering. Int $\mathrm{J}$ Biol Macromol. 201;48(4):571-576.

47. Zhang Y, Ouyang H, Lim CT, Ramakrishna S, Huang ZM. Electrospinning of gelatin fibers and gelatin/PCL composite fibrous scaffolds. J Biomed Mater Res. 2005;72B:156-65. doi:10.1002/jbm.b.30128].

48. Pant HR, Bajgai MP, Nam KT, Seo YA, Pandeya DR, Hong ST, et al. Electrospun nylon-6 spider-net like nanofiber mat containing TiO 2 nanoparticles: a multifunctional nanocomposite textile material. J Hazard Mater. 2011;185(1):124-30.

49. Ghasemi-Mobarakeh L, Prabhakaran MP, Morshed M, NasrEsfahani MH, Ramakrishna S. Electrospun poly $(\varepsilon-$ caprolactone)/gelatin nanofibrous scaffolds for nerve tissue engineering. Biomaterials. 2008;29(34):4532-9.
50. Guo Z, Pereira T, Choi O, Wang Y, Hahn HT. Surface functionalized alumina nanoparticle filled polymeric nanocomposites with enhanced mechanical properties. J Mater Chem. 2006;16(27):2800-8.

51. Francis L, Giunco F, Balakrishnan A, Marsano E. Synthesis, characterization and mechanical properties of nylon-silver composite nanofibers prepared by electrospinning. Curr Appl Phys. 2010;10(4):1005-8.

52. Jeon HJ, Kim JS, Kim TG, Kim JH, Yu WR, Youk JH. Preparation of poly ( $\varepsilon$-caprolactone)-based polyurethane nanofibers containing silver nanoparticles. Appl Surf Sci. 2008;254(18):5886-90.

53. Li SC, Li YN. Mechanical and antibacterial properties of modified nano- $\mathrm{ZnO} /$ high-density polyethylene composite films with a low doped content of nano-ZnO. J Appl Polym Sci. 2010;116:2965-9. 